\title{
Metabolic profiling and scavenging activities of developing circumscissile fruit of psyllium (Plantago ovata Forssk.) reveal variation in primary and secondary metabolites
}

\author{
Manish Kumar Patel ${ }^{1,2}$, Avinash Mishra ${ }^{1 *}$ (D) Santlal Jaiswar ${ }^{1}$ and Bhavanath Jha ${ }^{1 *}$
}

\begin{abstract}
Background: Developing fruit is considered as an excellent model to study the complex network of metabolites which are altered rapidly during development.

Results: Metabolomics revealed that developing psyllium fruit is a rich source of primary metabolites ( $\omega-3$ and $\omega-6$ fatty acids and amino-acids), secondary metabolites and natural antioxidants. Eidonomy and anatomy confirmed that psyllium fruit followed five stages of development. Total lipids and fatty acids were synthesized differentially; saturated fatty acids (FAs) increased, whereas total polyunsaturated FAs decreased with increasing developmental stage. The unsaturation index and degree of unsaturation showed a catenary curve. Principal component analysis confirmed a significant shift in the FA profile from bud initiation to the maturation stage. Similarly, a similar level of total amino acids was present at different developmental stage following a temporal biosynthesis pathway. Total phenolic and flavonoid contents decreased in tandem with fruit development. Twenty-two different metabolites were identified, and metabolic changes were also observed during fruit development. Six metabolites were detected exclusively in the flowering stage, whereas two were detected in each of early and maturity stages of development. The metabolites apigenin and kaempferol were detected ubiquitously in all developmental stages. Time-dependent metabolomics revealed a shift in metabolite biosynthesis.

Conclusion: During fruit development, metabolites, FAs, amino acids, total phenolics, total flavonoids, antioxidants and scavenging activities changed progressively and were co-ordinately linked to each other. As a future perspective, further studies will focus on the validation of identified metabolites, which integrated with transcriptomics data and will reveal the metabolic regulatory network of development psyllium fruit.
\end{abstract}

Keywords: Isabgul, Metabolite profiling, Plantago, Psyllium, Scavenging activity

\footnotetext{
*Correspondence: avinash@csmcri.org; avinash@csmcri.res.in;

avinashmishra11@rediffmail.com; jha.bhavanath@gmail.com

'Division of Applied Phycology and Biotechnology, CSIR- Central Salt and

Marine Chemicals Research Institute, G. B. Marg, Bhavnagar, Gujarat 364002,

India

Full list of author information is available at the end of the article
}

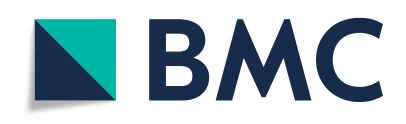

(- The Author(s). 2020 Open Access This article is licensed under a Creative Commons Attribution 4.0 International License, which permits use, sharing, adaptation, distribution and reproduction in any medium or format, as long as you give appropriate credit to the original author(s) and the source, provide a link to the Creative Commons licence, and indicate if changes were made. The images or other third party material in this article are included in the article's Creative Commons licence, unless indicated otherwise in a credit line to the material. If material is not included in the article's Creative Commons licence and your intended use is not permitted by statutory regulation or exceeds the permitted use, you will need to obtain permission directly from the copyright holder. To view a copy of this licence, visit http://creativecommons.org/licenses/by/4.0/. The Creative Commons Public Domain Dedication waiver (http://creativecommons.org/publicdomain/zero/1.0/) applies to the data made available in this article, unless otherwise stated in a credit line to the data. 


\section{Background}

Plantago ovata Forssk. is an ancient annual herbaceous plant species of the Plantaginaceae family and widely cultivated in tropical regions of the world [8]. Psyllium spp. has been used since ancient times for the treatment of many health conditions and diseases, such as inflammation, wound healing and cancer [29]. "Isabgol husk" represents the epidermal layer of the seed, which is a pharmaceutically important part of the plant. Husk is a natural laxative, contains mucilaginous compounds of medicinal values and is used as a thickening agent in the pharmaceutical industry. It is traditionally used as a prophylactic agent in the treatment of bowel obstruction, constipation, diarrhoea and dysentery [8].

Psyllium, the common name of the Plantago ovata, contains phenolics, flavonoids, terpenoids and iridoid glycosides [54]. The fruiting body of psyllium possesses powerful antioxidant compounds and is considered a rich source of natural antioxidants $[4,54]$. The flavonoids scutellarein 7-glucoside, scutellarein 7-glucuronide, scutellarein (5,6,7,4'-tetrahydroxyflavone), apigenin, luteolin, hispidulin (5,7,4' -trihydroxyS-methoxyflavone) and 5,7,4', 5 '-tetrahydroxyflavanone-3'-O-glucoside are widely reported from psyllium species $([14,17,21,28,35])$. Flavonoids are involved in mechanisms of defence against cardiovascular disease and in other in vitro antioxidant activities. More than 6000 varieties of flavonoids have been categorised, most of them reported from flowers, fruits and leaves of the plant [20]. Flavonoids interact with different types of enzymatic inhibitors, such as cyclooxygenase and lipoxygenase, which are involved in many biological activities, including antimicrobial, antihepatotoxic, antiosteoporotic, antiulcer, antiproliferative and apoptotic activities $[1,18]$. For example, quercetin-3-O- $\alpha-$ L-rhamnopyranoside obtained from Toona sinensis, showed antioxidant and anticancer activities [65], kaempferol and 8-C-(1,1- dimethyl-2-propen-1-yl)-5,7-dihydroxyflavonol isolated from Platanus orientalis and Platanus acerifolia showed osteoblastogenic as well as ER $\alpha$ mediated estrogenic activity [59], and kaempferol and hyperoside are the active compounds in seeds of Cuscuta chinensis, which have an osteogenic effect [62]. As a dietary or medicinal supplement, polyphenols and flavonoids contain health-promoting properties due to their antioxidant activities [10]. Heterogeneous compounds, such as polyphenols, are involved in antioxidant activities such as ABTS (2, 2'-azinobis-(3-ethylbenzothiazoline-6-sulfonic acid) scavenging, DPPH (2, 2-diphenyl-1-picrylhydrazyl) scavenging and hydroxyl radical scavenging [2].

Reactive oxygen species (ROS) are generated in response to stress, causing oxidative damage to the cell; therefore, plants exhibit robust defence mechanisms against ROS-induced oxidative stress [7, 25, 44, 60].
Several mechanisms are involved in free-radical scavenging activity, such as destruction of ROS formation by inhibition of enzymes that are involved in free-radical generation, ROS scavenging and protection by antioxidant defences [7, 40]. The plant metabolomics approach has been used to identify and quantify primary and secondary metabolites of medicinal plants [33, 39, 45]. Plant primary metabolites, such as fatty acids, amino acids and carbohydrates, are essential to life, whereas the production of secondary metabolites is co-ordinated with respect to plant development [42, 43]. Plant secondary metabolite contents are influenced by genotype, phenological stage and ecophysiological conditions [31]. The phenological stage is considered as the most important determining factor of the quality and quantity of metabolites from dietary, nutritional and pharmaceutical points of view and thus holds great significance [31]. Previously, we reported on comparative metabolic profiling of different plant parts (e.g. leaves, seeds and husks) of psyllium [45]. In the previous report, the nutraceutical potential of this plant was revealed, and it was also suggested that psyllium leaves could be used in a green salad as a dietary supplement to daily food [45]. Polysaccharides obtained from psyllium leaves, seed and husk have potential to be used as natural antioxidant and also have anti-proliferative activity [42, 43]. Seed development is an essential process of psyllium. Flower and seed development is characterized by structural changes, such as floral initiation, floral organ formation, floral differentiation and growth, leading to seed maturity [5]. The fruiting bodies of psyllium are a potent reservoir of primary and secondary metabolites. The organoleptic and nutritional qualities of a fruit are dependent on the total metabolite composition, which varies throughout the developmental stages [34]. Studying the chemical composition of developmental stages associated with specific metabolism and free-radical scavenging activity would be of immense importance. However, to the best of our knowledge, no research has been done, so far, on the metabolite profiling, scavenging analysis and morphological study of the developing fruiting body of psyllium. Therefore, the present study was carried out, and metabolite profiling of the developing fruit was performed to determine the potential candidate or appropriate harvesting time for the fruiting body of psyllium for nutraceutical applications. In the present study, metabolomics and scavenging activities of developing fruit were analysed using modern analytical tools and techniques [46] including gas chromatography-mass spectrometry (GCMS), high-performance liquid chromatography (HPLC) and liquid chromatography-mass spectrometry (LC-MS). The present study provides useful insight into the morphological, biochemical and metabolic responses of the developing fruiting body of psyllium. Furthermore, the 
present study will also provide guidance for the optimisation of the harvesting time of psyllium fruits and the maximisation of health benefits.

\section{Results \\ Eidonomy and anatomy of developing circumscissile capsule}

The colour of the fruiting body changed gradually from green to red throughout the different stages of development. Commonly, psyllium fruits reach maturity within 20 days and follow different developmental stages (Fig. 1). A total of five stages were observed: floral budding (stage-I; 0 day), floral organ initiation (stage-II; 4th day), floral organ formation (stage-III; 8th day), full flowering (stage-IV; 12th to 16th days) and fruit maturity (stage-V; 20th day). Eidonomy observations revealed that the inflorescence primordium originated from the axile of the leaves and developed into the spike primordium at later stages. In psyllium, a number of inflorescences ascended from the base of the plant (Fig. 1). Flowers were numerous, small and white; arranged in four spiral rows on the ovoid or cylindrical spikes and consisted of four sepals, four petals, four stamens and a pistil. Sepals were free, concave, glabrous and elliptic, whereas petals were glabrous, reflexed and white. The psyllium ovary was free and bilocular (single ovule per locule) with axile placentation. Acropetalous types of inflorescences, in which older flowers grew towards the base while younger flowers were at the growing end, were observed in psyllium. At the early stage of inflorescence development (stage I, 0 day), the spike was $5 \mathrm{~mm}$ in length, and the transverse section showed an initial stage of five flower differentiations. Of these, three flowers showed developing sepals, petals and stamens, whereas two contained sepal and petal primordia. An initiation of anther with four stamens and gynoecium was detected at stage II (4th day), which was clearly seen in later stages of development (stage III, 8th day onwards). Seed development was initiated from stage IV (12th to 16th days), and fruit reached maturity on the 20th day of development (stage V). The mature fruit of psyllium is known as a circumscissile capsule, which is divided horizontally into two parts during dehiscence from the equator to release the seeds (Fig. 2). Psyllium seeds are translucent, hard, yellowish brown, smooth, boat-shaped and covered with a mucilage layer. The presence of a hilum was noticed on the concave (ventral) side of the seed, which was covered with a thin, white membrane (Fig. 2). Seeds did not emit any odour or have any taste, but the succulent part was bitter and astringent. The transverse section of a mature seed revealed differentiated endosperm, embryo, pigment layer and epidermis (Fig. 2).

\section{Fatty acids differentially synthesized in developing fruiting body}

The total lipid and fatty-acid (FA) composition were identified and quantified at different developmental stages $(0,4$ th, 8th, 12th, 16th and 20th days) of psyllium fruit (Table 1). The maximum content of saturated FA (SFA) was detected at stage I (0 day; 49.7\%) and declined up to stage III (8th day), at which was found the lowest content (25.7\%), after which it increased, reaching up to $33.7 \%$ at maturity (stage V, 20th day). In contrast, the total polyunsaturated fatty acid (PUFA) increased with developmental stage and reached a maximum at the 8th day (stage III; 72.5\%), thereafter decreasing with increasing developmental stage. Among PUFAs, C18 PUFAs were dominant (48-71\% of total FAs) over C20, which were found in traces (about $0.5-2 \%$ of total FAs) in the developing fruiting bodies. The unsaturation index (UI) and degree of unsaturation (DU) showed a catenary curve with maximum values of 188.3 and 146.9 , respectively at stage III (8th day).

A range of FAs (C12-C24) were detected, dominanted by linoleic acid (C18:2, n-6; 26-38\%), linolenic acid (C18:3, n-3 or $\mathrm{n}-6 ; 20-35 \%)$ and palmitic acid (C16:0; 20-32\%) in the developing fruit of psyllium (Table 1). Five FAs, palmitic acid (C16:0), gamma-linolenic acid (C18:3, n-6), alpha-linolenic acid (C18:3, n-3), stearic acid (C18:0) and cis-11-eicosenoic acid (C20:1, n-9), decreased with fruit development. In contrast, linoleic acid $(\mathrm{C} 18: 2, \mathrm{n}-6)$ increased with developmental stages and reached a maximum at fruit maturity $(38.8 \%)$. Four FAs, lauric acid (C12:0), myristoleic (C14:1), cis-10-heptadecanoic acid (C17:1, n-7) and tricosanoic acid (C23:0), were detected exclusively at the later stage of development (stage IV and V; 12th-16th and 20th days). Notably, two FAs myristic acid (C14:0) and cis-11,14,17eicosadienoic acid (C20:3, n-3), were found in all stages of fruit development but disappeared at maturity (stage $\mathrm{V}, 20$ th day). No remarkable changes were detected in the remaining minor FAs during fruit development (Table 1). Principal component analysis (PCA) indicated that the total lipid and fatty acid contents were significantly correlated with the different developmental stages of the fruit, and the heat map showed the differential fatty acid composition (Fig. 3).

The bi-plot based on PC1 and PC2 showed the possible linkage of FA composition to different stages of development and explained $83.2 \%$ of the variation (Fig. 3a). The bi-plot showed that total lipid and FAs were grouped into four clusters. There was a significant shifting of FA composition from bud initiation (stage I: 0 day) to maturity (stage V: 20th day). Overall, PCA exhibited statistically significant differences in lipid and FA composition between developmental stages. There was a significant change from stage I (0 day) to stage III (8th 


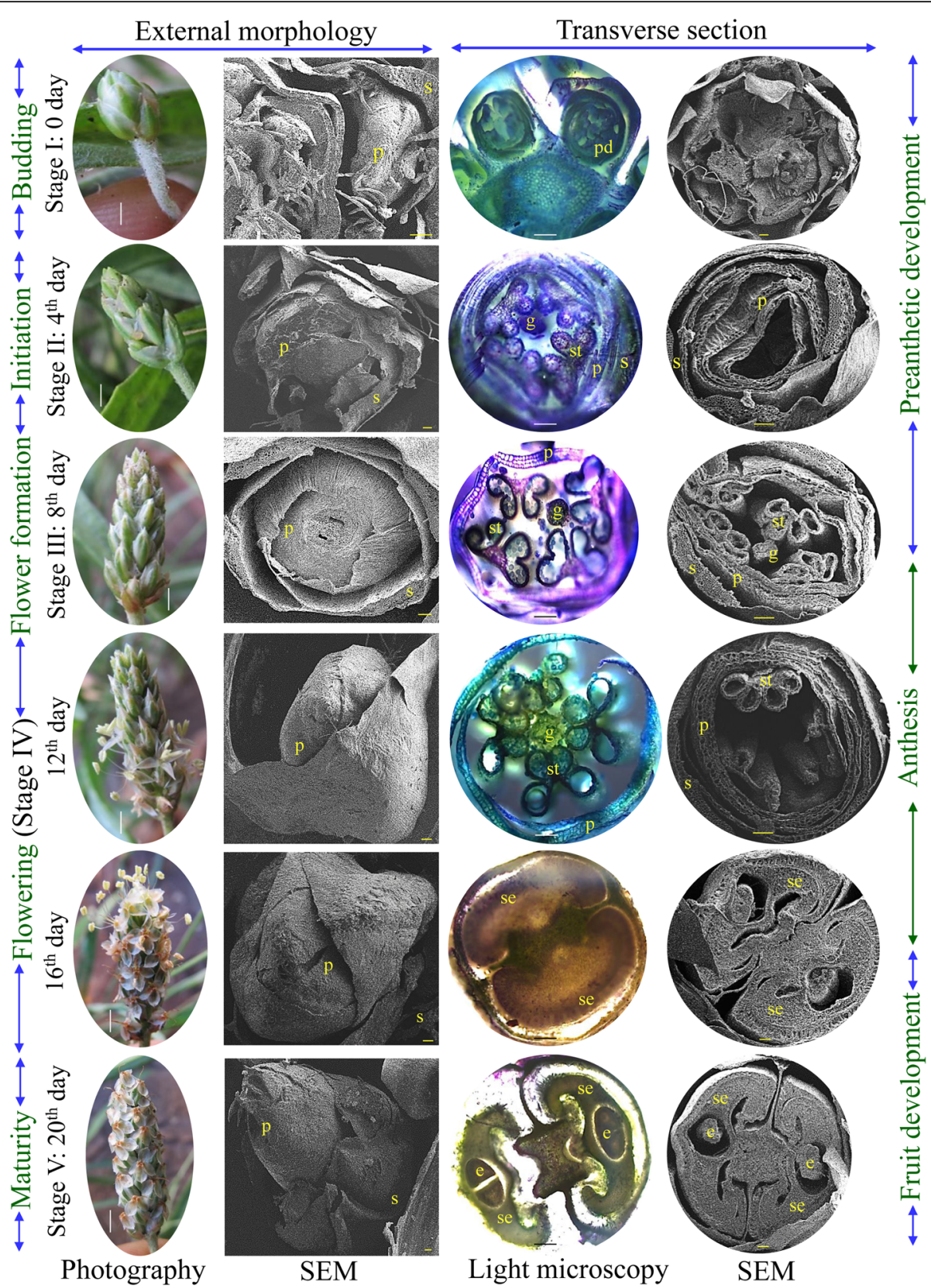

Fig. 1 Flower development of psyllium (Plantago ovata). Eidonomy and anatomy studies were monitored from flower bud induction (day zero) to fruit maturity (day twenty) under photography and scanning electron microscopy. Abbreviations: e, embryo; g, gynoecium; p, petal; pd., presnthetic development; s, sepal; se, seed endosperm; st, stamens. Scale bar of first column (i.e. photography) shows $0.5 \mathrm{~cm}$ while others represent $0.1 \mathrm{~mm}$

day via stage II, 4th day), but no significant correlation was found from stage III (8th day) to stage IV (12th to 16th days); thereafter a significant change was again noticed from stage IV (12th to 16th days) to stage V (20th day). These observations were also supported by the heat map, which showed significant differences in FA and lipid composition (Fig. 3b).

\section{Amino acid constituents revealed temporal metabolic pathways}

In total, 16 amino acids were detected, quantified in the different developing stages of psyllium fruit and categorized as non-essential, essential, sulphur-rich and aromatic amino acids (Supplementary Table S1). A similar level of total amino acids was present at various 


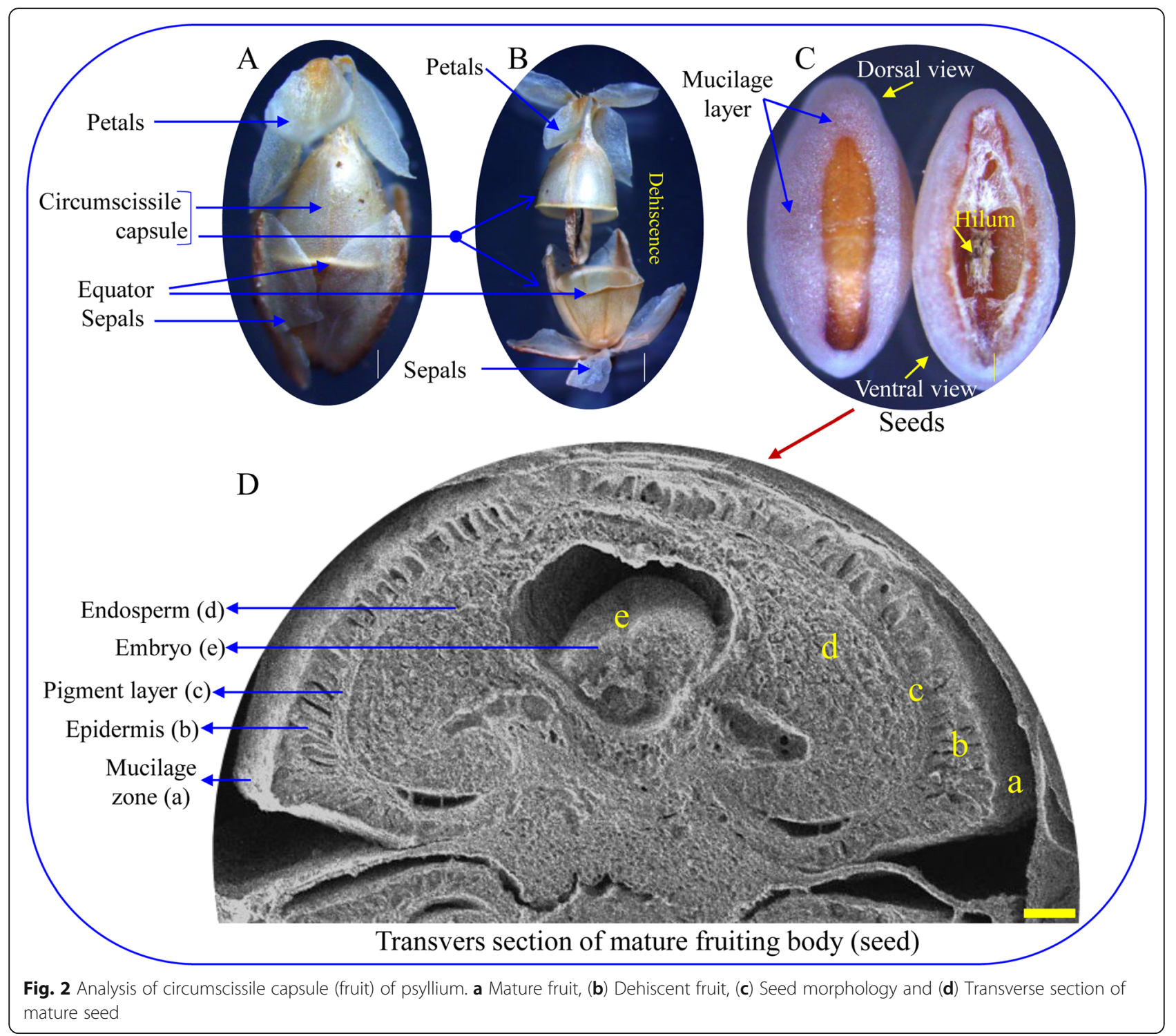

developmental stages, and a possible temporal aminoacid pathway was illustrated (Fig. 4). The essential amino acids, lysine (20-33\%) and isoleucine (7-23\%) were predominant in the developing psyllium fruit, followed by the non-essential amino acid proline (10-21\%) and sulphurrich methionine (15-21\%) and cysteine (5-19\%). The non-essential amino acids aspartate, glutamine and glycine were increased with fruit development up to full flowering (stage IV, 12th-16th days); thereafter, a sudden decrease was noticed at maturity (stage $\mathrm{V}, 20$ th day). In contrast, an abrupt change in contents of alanine, arginine and serine were observed at different developmental stages, but the maximum levels were detected at maturity. A similar pattern was also noted with the essential amino acids histidine and threonine. However, leucine content was at a maximum at the 16th day of fruit development. The aromatic amino acid phenylalanine was detected in minor quantities, whereas tyrosine was found exclusively at the 4th day and at maturity (i.e. the 20th day). The percent contents of abundant amino acids proline, isoleucine and methionine were decreased at maturity, and in contrast, an elevated amount of lysine was detected.

\section{Total phenolic and flavonoid contents decrease concomitantly with development of fruit}

The highest total phenolic and flavonoid contents were detected at the bud initiation stage, after which they decreased concomitantly with increasing developmental stage and reached a minimum at maturity (Fig. 5). Statistically, a fourth-order polynomial trend line with a regression value about 0.99 clearly demarcated different stages of fruit development and followed a decreasing trajectory path. 
Table 1 Total lipid and fatty acid composition of developing fruiting body of psyllium

\begin{tabular}{|c|c|c|c|c|c|c|c|}
\hline Fatty acids & Name of fatty acids & $\begin{array}{l}0 \text { day } \\
\text { (Stage I) }\end{array}$ & $\begin{array}{l}\text { 4th day } \\
\text { (Stage II) }\end{array}$ & $\begin{array}{l}\text { 8th day } \\
\text { (Stage III) }\end{array}$ & $\begin{array}{l}\text { 12th day } \\
\text { (Stage IV) }\end{array}$ & $\begin{array}{l}\text { 16th day } \\
\text { (Stage IV) }\end{array}$ & $\begin{array}{l}\text { 20th day } \\
\text { (Stage V) }\end{array}$ \\
\hline \multicolumn{8}{|c|}{ Lipid composition } \\
\hline$\sum$ SFA & & $49.71 \pm 1.46$ & $30.12 \pm 1.98$ & $25.66 \pm 0.45$ & $28.43 \pm 0.65$ & $31.14 \pm 1.25$ & $33.65 \pm 2.86$ \\
\hline$\sum$ MUFA & & $2.31 \pm 0.72$ & $1.96 \pm 0.01$ & $1.84 \pm 0.01$ & $1.73 \pm 0.08$ & $2.07 \pm 0.13$ & $3.16 \pm 0.93$ \\
\hline$\Sigma$ PUFA & & $47.98 \pm 0.74$ & $67.92 \pm 1.99$ & $72.51 \pm 0.44$ & $69.84 \pm 0.73$ & $66.79 \pm 1.38$ & $63.18 \pm 3.80$ \\
\hline$\sum 18$ PUFA & & $47.61 \pm 0.75$ & $66.78 \pm 2.20$ & $70.61 \pm 0.81$ & $68.19 \pm 0.85$ & $65.4 \pm 1.85$ & $61.48 \pm 4.96$ \\
\hline$\sum 20$ PUFA & & $0.37 \pm 0.01$ & $1.14 \pm 0.21$ & $1.90 \pm 0.37$ & $1.64 \pm 0.13$ & $1.39 \pm 0.46$ & $1.70 \pm 1.17$ \\
\hline UI & & $119.25 \pm 0.51$ & $174.56 \pm 3.91$ & $188.25 \pm 0.91$ & $180.57 \pm 0.09$ & $171.52 \pm 3.75$ & $153.78 \pm 8.15$ \\
\hline DU & & $98.26 \pm 2.21$ & $137.8 \pm 3.97$ & $146.85 \pm 0.88$ & $141.41 \pm 1.38$ & $135.64 \pm 2.63$ & $129.53 \pm 6.66$ \\
\hline n6/n3 & & $1.3 \pm 0.24$ & $1.10 \pm 0.05$ & $1.01 \pm 0.01$ & $1.00 \pm 0.09$ & $1.05 \pm 0.06$ & $2.10 \pm 0.17$ \\
\hline $\mathrm{n} 9 / \mathrm{n} 3$ & & $0.11 \pm 0.04$ & $0.06 \pm 0.01$ & $0.05 \pm 0.01$ & $0.04 \pm 0.01$ & $0.06 \pm 0.01$ & $0.14 \pm 0.06$ \\
\hline n9/n6 & & $0.08 \pm 0.02$ & $0.06 \pm 0.01$ & $0.05 \pm 0.01$ & $0.04 \pm 0.01$ & $0.05 \pm 0.01$ & $0.06 \pm 0.03$ \\
\hline Al & & $31.29 \pm 3.11$ & $38.72 \pm 0.39$ & $39.72 \pm 0.79$ & $38.14 \pm 0.54$ & $38.86 \pm 0.77$ & $48.01 \pm 0.93$ \\
\hline $\mathrm{TI}$ & & $97.73 \pm 4.25$ & $120.52 \pm 0.48$ & $129.41 \pm 0.67$ & $128.12 \pm 3.31$ & $122.46 \pm 2.25$ & $87.19 \pm 4.95$ \\
\hline \multicolumn{8}{|c|}{ Fatty acids composition } \\
\hline C12:0 & Lauric acid & n.d & n.d & n.d & n.d & $0.77 \pm 0.59$ & $0.63 \pm 0.21$ \\
\hline C14:0 & Myristic acid & $0.27 \pm 0.01$ & $0.17 \pm 0.02$ & $0.16 \pm 0.02$ & $0.24 \pm 0.01$ & $0.29 \pm 0.01$ & n.d \\
\hline C14:1 & Myristoleic acid & n.d & n.d & n.d & n.d & n.d & $0.14 \pm 0.02$ \\
\hline C15:0 & Pentadecanoic acid & $0.20 \pm 0.01$ & $0.18 \pm 0.01$ & $0.2 \pm 0.02$ & $0.23 \pm 0.01$ & $0.26 \pm 0.01$ & $0.22 \pm 0.02$ \\
\hline C16:0 & Palmitic acid & $32.53 \pm 0.73$ & $22.61 \pm 0.39$ & $20.23 \pm 0.28$ & $21.96 \pm 0.11$ & $23.68 \pm 0.97$ & $24.53 \pm 0.46$ \\
\hline C16:1 (n-7) & Palmitoleic acid & n.d & n.d & $0.19 \pm 0.01$ & $0.18 \pm 0.02$ & $0.24 \pm 0.01$ & $0.27 \pm 0.02$ \\
\hline C17:0 & Heptadecanoic acid & $0.18 \pm 0.01$ & $0.16 \pm 0.01$ & $0.18 \pm 0.01$ & $0.20 \pm 0.02$ & $0.25 \pm 0.01$ & $0.23 \pm 0.01$ \\
\hline C17:1 (n-7) & Cis-10-Heptadecanoic acid & n.d & n.d & n.d & n.d & n.d & $0.06 \pm 0.02$ \\
\hline C18:0 & Stearic acid & $15.31 \pm 0.91$ & $5.37 \pm 1.62$ & $3.41 \pm 0.61$ & $4.15 \pm 0.55$ & $4.44 \pm 0.60$ & $6.55 \pm 2.48$ \\
\hline C18:1 (n-9) & Oleic acid & $2.14 \pm 0.72$ & $1.47 \pm 0.07$ & $1.41 \pm 0.05$ & $1.34 \pm 0.10$ & $1.65 \pm 0.13$ & $2.65 \pm 0.97$ \\
\hline C18:2 (n-6) & Linoleic acid & $26.88 \pm 2.46$ & $30.66 \pm 2.02$ & $30.82 \pm 0.44$ & $30.38 \pm 2.00$ & $30.66 \pm 0.30$ & $38.84 \pm 2.31$ \\
\hline$C 18: 3(n-6)$ & gamma-Linolenic acid & $20.73 \pm 1.16$ & $4.58 \pm 0.19$ & $4.72 \pm 0.21$ & $3.80 \pm 0.01$ & $3.16 \pm 0.31$ & $2.16 \pm 0.43$ \\
\hline C18:3 (n-3) & alpha-Linolenic acid [ALA] & n.d & $31.54 \pm 0.48$ & $35.07 \pm 0.69$ & $34.02 \pm 1.03$ & $31.57 \pm 1.97$ & $20.49 \pm 2.11$ \\
\hline C20:0 & Arachidic acid & $0.67 \pm 0.04$ & $0.76 \pm 0.03$ & $0.71 \pm 0.01$ & $0.74 \pm 0.06$ & $0.70 \pm 0.06$ & $0.52 \pm 0.01$ \\
\hline C20:1 (n-9) & Cis-11-Eicosenoic acid & $0.17 \pm 0.01$ & $0.50 \pm 0.06$ & $0.23 \pm 0.04$ & $0.21 \pm 0.01$ & $0.19 \pm 0.01$ & $0.04 \pm 0.01$ \\
\hline$C 20: 2$ & Cis-11,14-Eicosadienoic acid & $0.11 \pm 0.02$ & $0.51 \pm 0.03$ & $0.28 \pm 0.03$ & $0.30 \pm 0.01$ & $0.25 \pm 0.04$ & $0.10 \pm 0.01$ \\
\hline$C 20: 3(n-6)$ & Cis-8,11,14-Eicosatrienoic acid & n.d & n.d & $0.74 \pm 0.42$ & $0.47 \pm 0.22$ & $0.29 \pm 0.37$ & $1.61 \pm 1.01$ \\
\hline$C 20: 3(n-3)$ & Cis-11,14,17-Eicosadienoic acid & $0.26 \pm 0.16$ & $0.63 \pm 0.06$ & $0.87 \pm 0.01$ & $0.87 \pm 0.01$ & $0.85 \pm 0.12$ & n.d \\
\hline C21:0 & Heneicosanoic acid & n.d & n.d & n.d & $0.05 \pm 0.01$ & $0.04 \pm 0.02$ & $0.05 \pm 0.01$ \\
\hline C22:0 & Behenic acid & $0.33 \pm 0.01$ & $0.52 \pm 0.05$ & $0.43 \pm 0.02$ & $0.42 \pm 0.05$ & $0.38 \pm 0.05$ & $0.27 \pm 0.02$ \\
\hline C23:0 & Tricosanoic acid & n.d & n.d & n.d & $0.10 \pm 0.01$ & n.d & $0.07 \pm 0.01$ \\
\hline C24:0 & Lignoceric acid & $0.23 \pm 0.01$ & $0.35 \pm 0.06$ & $0.32 \pm 0.02$ & $0.34 \pm 0.03$ & $0.31 \pm 0.05$ & $0.18 \pm 0.02$ \\
\hline
\end{tabular}

Value(\%) in mean \pm SE; SFA: saturated fatty acids; MUFA: mono unsaturated fatty acids; PUFA: poly unsaturated fatty acids; UI: unsaturation index; DU: degree of unsaturation; Al: Atherogenic index; Tl: Thrombogenic index nd: not detected; All experiments were carried out three times, each with three biological replicates

Total antioxidant and scavenging activities of developing fruit

The antioxidant and scavenging activities of the developing fruit extracts increased concomitantly with the extract concentration (Fig. 6). The total antioxidant activity (expressed as the \% radical cation $\mathrm{ABTS}^{+}{ }^{+}$scavenging activity) was found to be the highest in stage II (4th day) in a lower extract concentration range $(20-40 \mu \mathrm{g})$, whereas stage I (0 day) showed maximum activity in a higher extract concentration range $(60-100 \mu \mathrm{g})$. It was noticed that developing fruit showed similar activity (94\%) up to stage IV (12th-16th days), after which a lower 

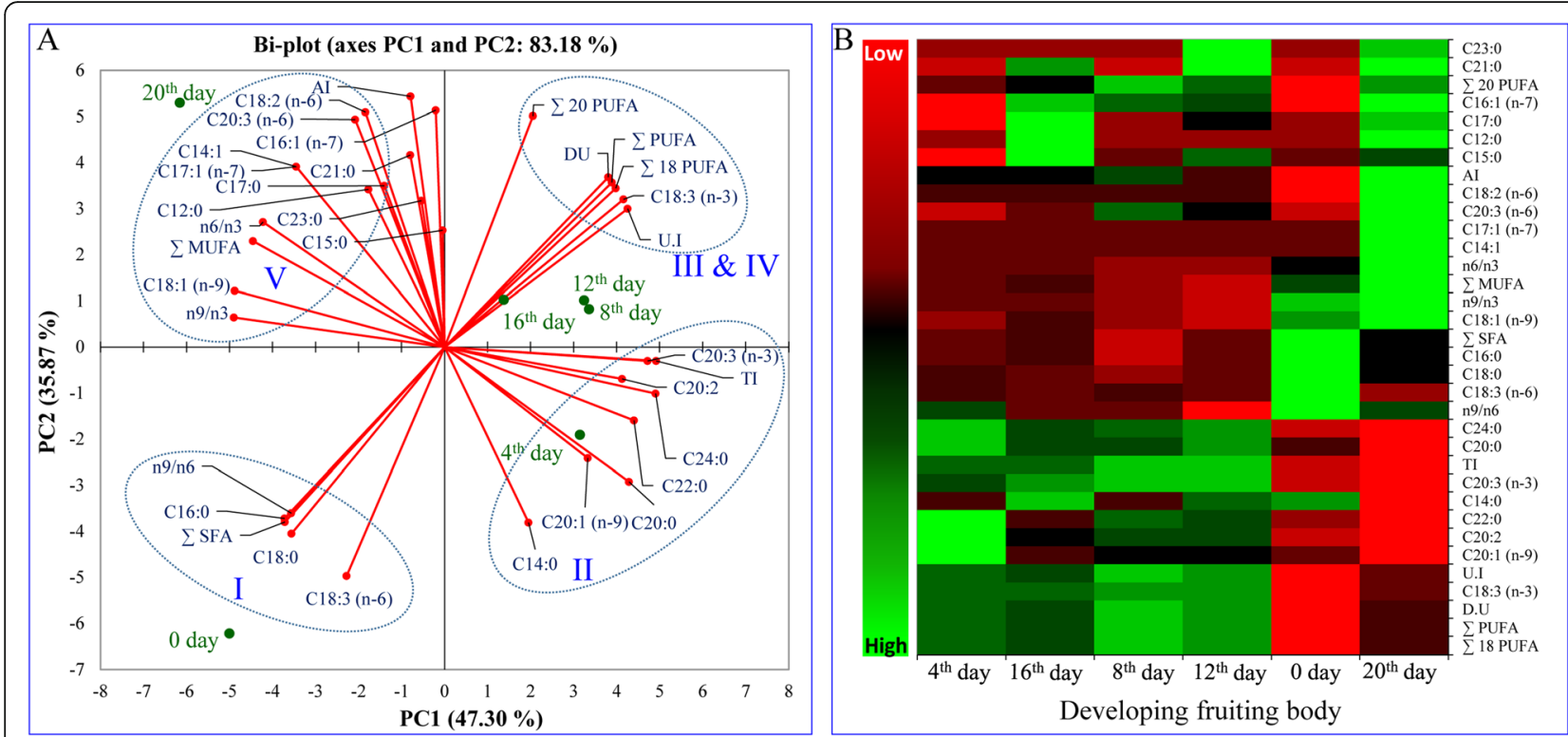

Fig. 3 Principal component analysis (PCA) and heat map of total lipids and fatty acids of developing fruit of psyllium. a Bi-plot obtained from PCA of data matrix according to Table 1 with first two principal components. b Heat map of the differentially synthesised total lipids and fatty acids. All experiments were carried out three times, each with three biological replicate sets and each set contained three replicates. The colors (green to red via black) of the tiles in the heat map represent the values varying from high to low

activity (72\%) was observed with mature fruit extract at the maximum concentration $(100 \mu \mathrm{g})$ used in the study (Fig. 6a). The maximum DPPH scavenging activity was detected in fruit extract of stage IV (16th day) of development, followed by stage III (8th day) and IV (12th day). About $88 \%$ scavenging activity was observed with $100 \mu \mathrm{g}$ extract of all developing fruiting bodies (Fig. 6b).

\section{Metabolite profiling of developing circumscissile capsule}

Nineteen different metabolites (Supplementary Table S2) were identified in the various developmental stages of psyllium fruit (Fig. 7). In total, 10 flavonoids and 2 alkaloids with antioxidant properties were detected (Supplementary Table S3). Two flavonoids, apigenin 7rhamnoside (m/z 381.10) and kaempferol 3-(2",3"-diacetylrhamnoside)-7-rhamnoside ( $\mathrm{m} / \mathrm{z}$ 663.19), were ubiquitous in all developmental stages. Two metabolites, catechin pentaacetate $(\mathrm{m} / \mathrm{z} 483.13)$ and myricetin $3,7,3^{\prime}$, 5 '-tetramethyl ether $(\mathrm{m} / \mathrm{z} 339.09)$, were detected in the early developmental stages (stage I, 0 day and II, 4th day) only. Similarly, two metabolites, sampangine (m/z 197.05) and syzyginin B (m/z 721.07), were detected in stage III (8th day) only. A total of four metabolites-brassicasterol (m/z 381.35), cyanidin 3-[6-(4-glucosylcoumaryl) sophoroside] 5-glucoside (m/z 541.66), punicalin ( $\mathrm{m} / \mathrm{z} 815.1)$ and $\beta$-tocopherol (m/z 381.35)-were detected exclusively in stage IV (16th day) of fruit development. Similarly, two antioxidant metabolites-dictyoquinazol C (m/z 325.1) and 3-O-Caffeoyl-1-methylquinic acid (, m/z 185.061)were only identified in mature fruit (stage V, 20th day).
The remaining metabolites were detected at different levels depending of the fruit developmental stages.

\section{Discussion}

Flowering plants have an enormous diversity of floral organization and widely variable morphological characteristics. Flower development is a highly coordinated phenomenon, and metabolomics of the model plant Arabidopsis revealed that distinct metabolic pathways were stimulated at different stages of flower development [37]. Structural changes characteristic of organ development and the developing flower or fruit are attributed to floral bud initiation, floral organ initiation, floral differentiation and growth leading to seed maturity [5].

Plantago flowers are actinomorphic, and the phylogenetic position of Plantago makes it a model system to study the molecular developmental mechanism correlated with the loss of dorsal-specific CYC-like gene function [50]. Protogynous is the most distinctive characteristic of Plantago lanceolata flowering, in which stigmas are exuded and become receptive before the anthers mature. In the present study, the acropetalous type of inflorescence was observed [52], and anthers were developed in stage II (4th day), whereas growth of the gynoecium was detected later at stage III (8th day) (Fig. 1). After maturity (stage V, 20th day), the characteristic psyllium fruit was developed as a circumscissile capsule, which is small, ovate in shape and dehiscing horizontally through its equator (Fig. 2). Commonly, sepals and petals are attached to the capsule, and the mature seed is covered with a mucilage layer 


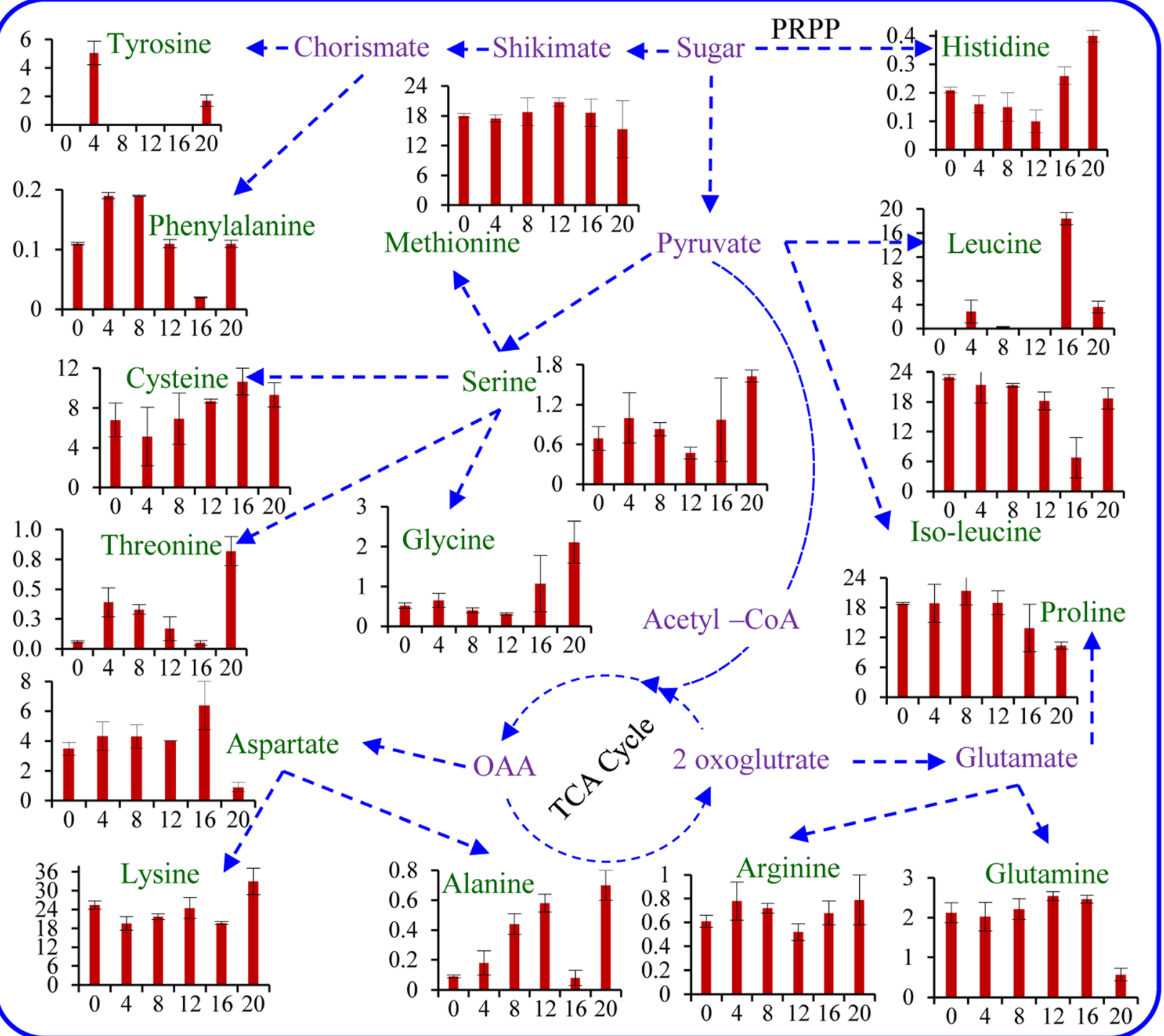

Fig. 4 Temporal amino acid pathway inferred in the developing fruit of psyllium. X-axis and Y-axis represent days of fruit development and quantitative mean value (\%), respectively as per Table S1. All experiments were carried out three times, each with three biological replicate sets and each set contained three replicates

containing hilum. The capsule (fruit) is a small pyxidium and covered by the persistent corolla [52].

Different psyllium plant parts, including leaves, seeds and husk, are considered a rich source of essential FAs, i.e. nutritive PUFAs [45], which cannot be synthesized de novo in humans and are thus required to be outsourced from food [16]. In the present study, developing fruits were found to be a rich source of essential $\omega-3$ alpha-linolenic (ALA) and $\omega-6$ linoleic (LA) and gammalinolenic (GLA) acids. Similar to the development of Camelina sativa fruit, most of the fatty acid profiles of the early stages were different to that of mature stages [51]. A bi-plot data matrix revealed a correlation between FAs and different developmental stages (Fig. 3). A significant shift in lipid and FA composition was noticed from one developmental stage to another, similar to that in Camelina sativa [51]. A previous bi-plot analysis confirmed statistically significant differences in lipid and FA composition between different plant parts [45].

In the early stage of development, high levels of SFAs were detected which declined at a later stage (maturity). In contrast, an elevated content of PUFAs, including ALA, LA and GLA, were found in the middle stages of development (Table 1). Among the PUFAs, ALA is extensively explored for a wide range of biological activities, such as nootropic and prophylactic effects, including anti-hyperlipidemic, anti-inflammatory, antithrombotic and anti-hypertensive effects $[16,23]$. A high 


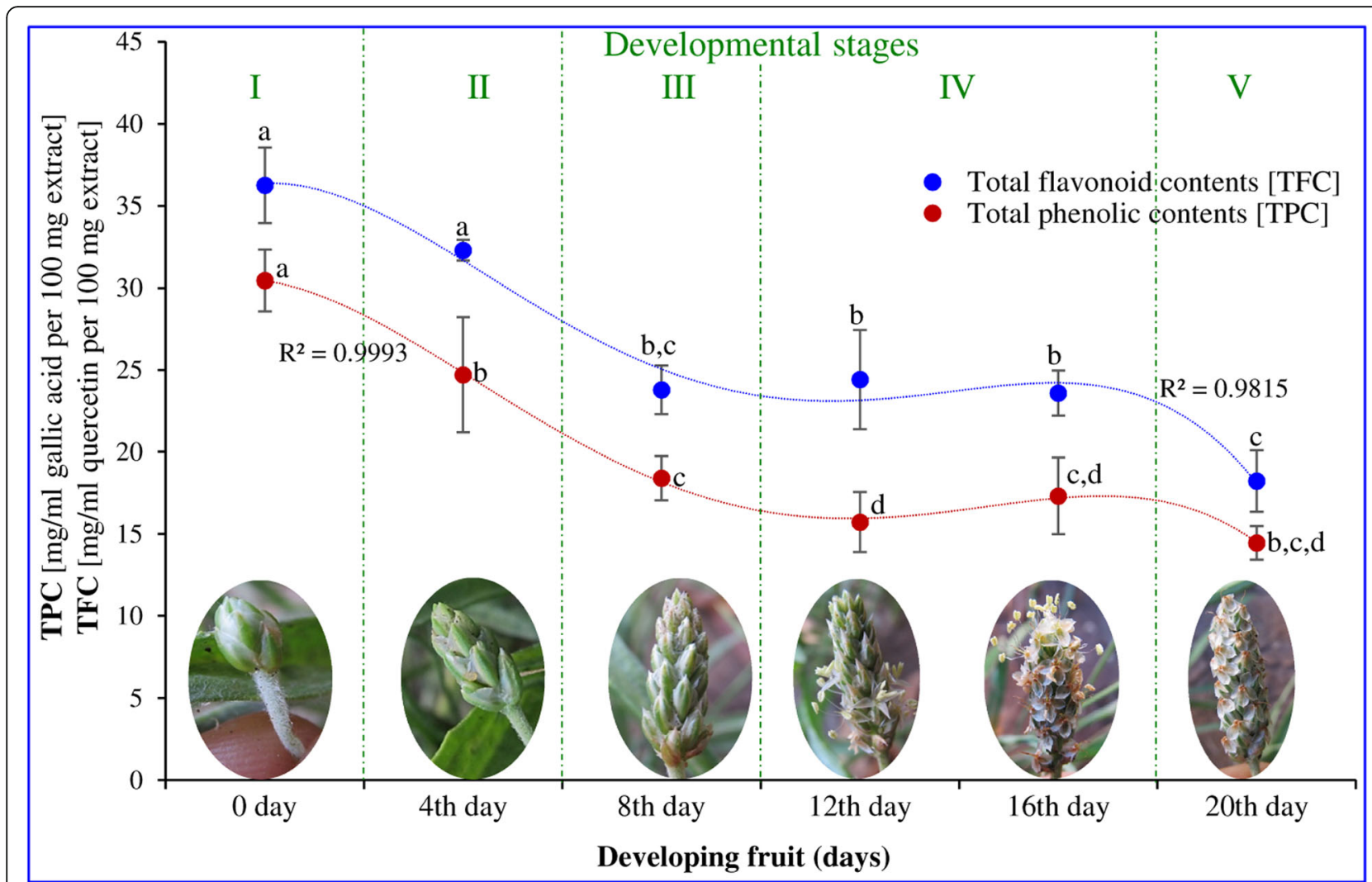

Fig. 5 Total flavonoid and total phenolic contents extracted from developing fruiting body of psyllium. All experiments were carried out three times, each with three biological replicate sets and each set contained three replicates. Value represents the mean \pm SE and values with different letters are significant different at $p<0.05$

atherogenicity index (AI) value favours the adhesion of lipids to the cells; in contrast, a lower AI value inhibits aggregation and levels of esterified fatty acid. Similarly, the thrombogenicity index (TI) also indicates a relationship between SFA and UFA with respect to forming clots in the blood vessels. A high value promotes clotting, whereas a lower value leads to an anti-thrombogenic (anti-clotting) property.

There are many naturally occurring biologically active peptides with the potential to be used in drug development [19]. In total, 16 primary metabolites (amino acids) were identified and quantified in the different developmental stages of psyllium fruit (Supplementary Table S1). The amino acid level was coincident with fruit development, and revealed a possible temporal amino-acid pathway (Fig. 4). A spatial occurrence of amino acids was reported from different plants, including Cumin, Salicornia and Plantago spp. [33, 39, 45]. Similar to the observation in developing psyllium fruit, some amino acids increased, whereas others decreased at early stages of tomato development; on the other hand, an increase in certain amino acids was found during strawberry and peach development $[6,15,30]$. All developmental stages were dominated by the essential amino acids lysine (20-33\%) and isoleucine (7-23\%). Similarly, sulphur-rich methionine (15-21\%) and cysteine (5-19\%) were abundant compared with other amino acids. Similarly, the levels of methionine in tomato and strawberry did not change significantly during development of fruit and ripening [38, 64]. Interestingly, the non-essential amino acids aspartate, glutamine and glycine were increased with fruit development but finally declined at maturity, whereas alanine, arginine, serine, histidine and threonine were detected at the highest levels in the maturity stage. Major amino acids serine, glycine, glutamate, glutamine and leucine were detected throughout seed development in A. thaliana [3]. The amino acids alanine, glycine, serine, leucine, lysine, threonine and cysteine were specifically accumulated during later stages of development (stages IV and V; 12th-16th and 20th days), and it was hypothesised that these are involved in protein biosynthesis. Additionally, they may serve as precursors to a number of important metabolic pathways.

Among the natural antioxidants, widely distributed plant flavonoids and phenolic constituents merit emphasis because of their involvement in cellular plant 

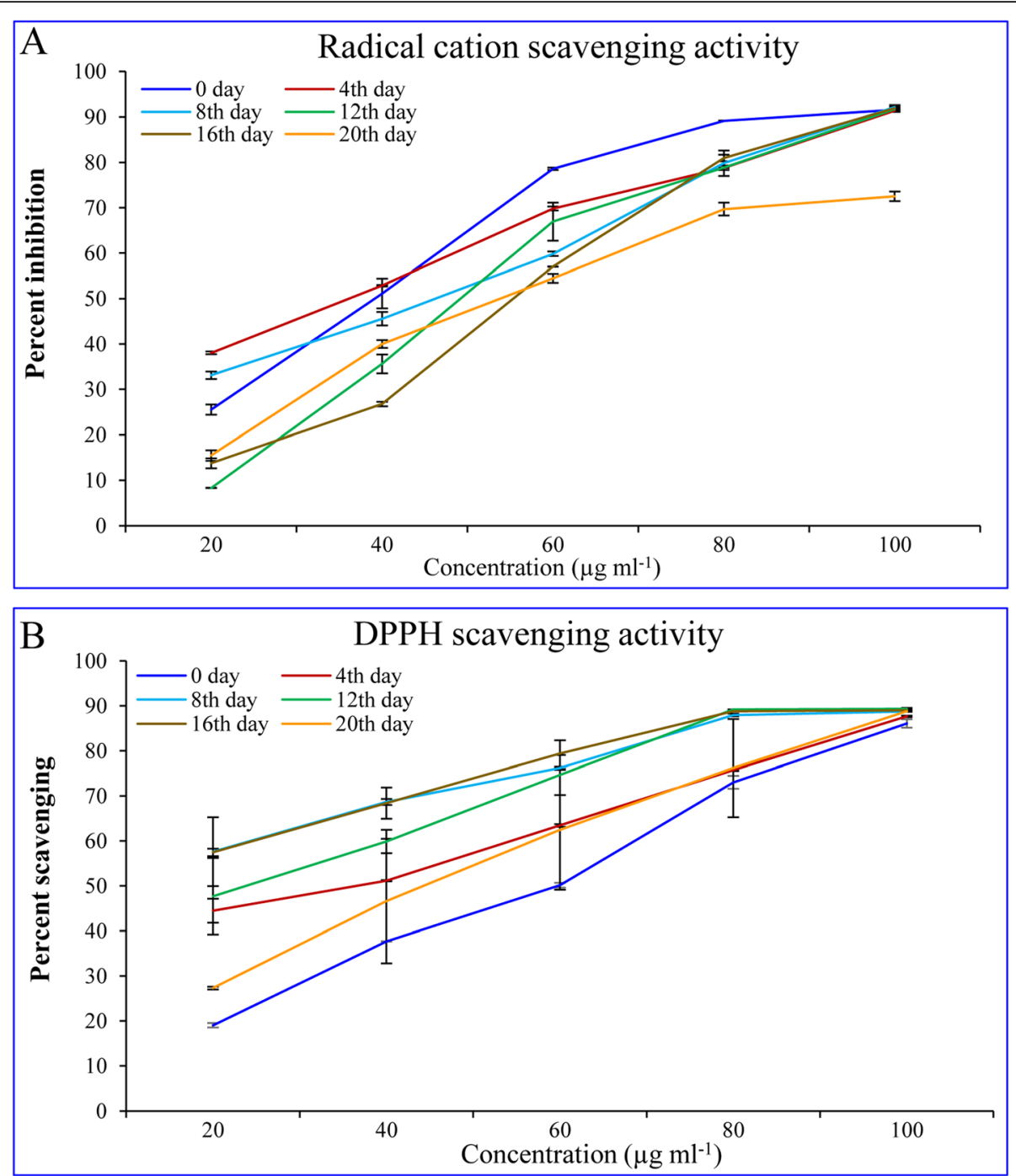

Fig. 6 Total antioxidant and scavenging activities of developing fruit of psyllium. a Total antioxidant (expressed as the \% radical cation ABTS.+ scavenging activity) and (b) DPPH scavenging activities. All experiments were carried out three times, each with three biological replicate sets and each set contained three replicates. Value represents the mean \pm SE

defence systems and are therefore considered as potent antioxidants [13, 33, 57]. Psyllium plant parts contained higher contents of total flavonoids and total phenols and possessed high antioxidant and scavenging activities [45]. In this study, total phenolic and flavonoid contents were decreased concomitantly with developmental stages of the fruit (Fig. 5). Similarly, concentration-dependent total antioxidant and scavenging activities varied according to the different stages of fruit development (Fig. 6). During different developmental stages of in vitro callus culture of $P$. ovata, total antioxidant and scavenging activities increased concurrently with phenolic and flavonoid contents [56]. These results are in accordance with the scavenging and antioxidant activities of Plantago plant parts, and polysaccharide, which showed a direct correlation with phenolic and flavonoid contents [42, 43, 45]. The loading plot of primary metabolites, total flavonoids and phenolic contents confirmed the shift in metabolites from stage I (bud initiation, 0 day) to stage $\mathrm{V}$ (maturity, 20th day) through different intermediates (Supplementary Figure S1).

Several metabolic changes were observed during developmental stages of psyllium fruit (Fig. 7 and Supplementary Table S3). Out of 19 identified metabolites (Supplementary Table S2), 4 of them-brassicasterol, cyanidin 3-[6-(4-glucosylcoumaryl) sophoroside] 5glucoside, punicalin and $\beta$-Tocopherol -were detected exclusively during flowering (stage IV, 16th day). Most of the phytosterols identified in vegetable oils. The brassicasterol is a free sterol and it show the natural antioxidant activities in foods $[9,36]$, whereas 2 antioxidant metabolites-dictyoquinazol $\mathrm{C}$ and 3-O-Caffeoyl-1methylquinic acid (MCGA3)-were detected during 


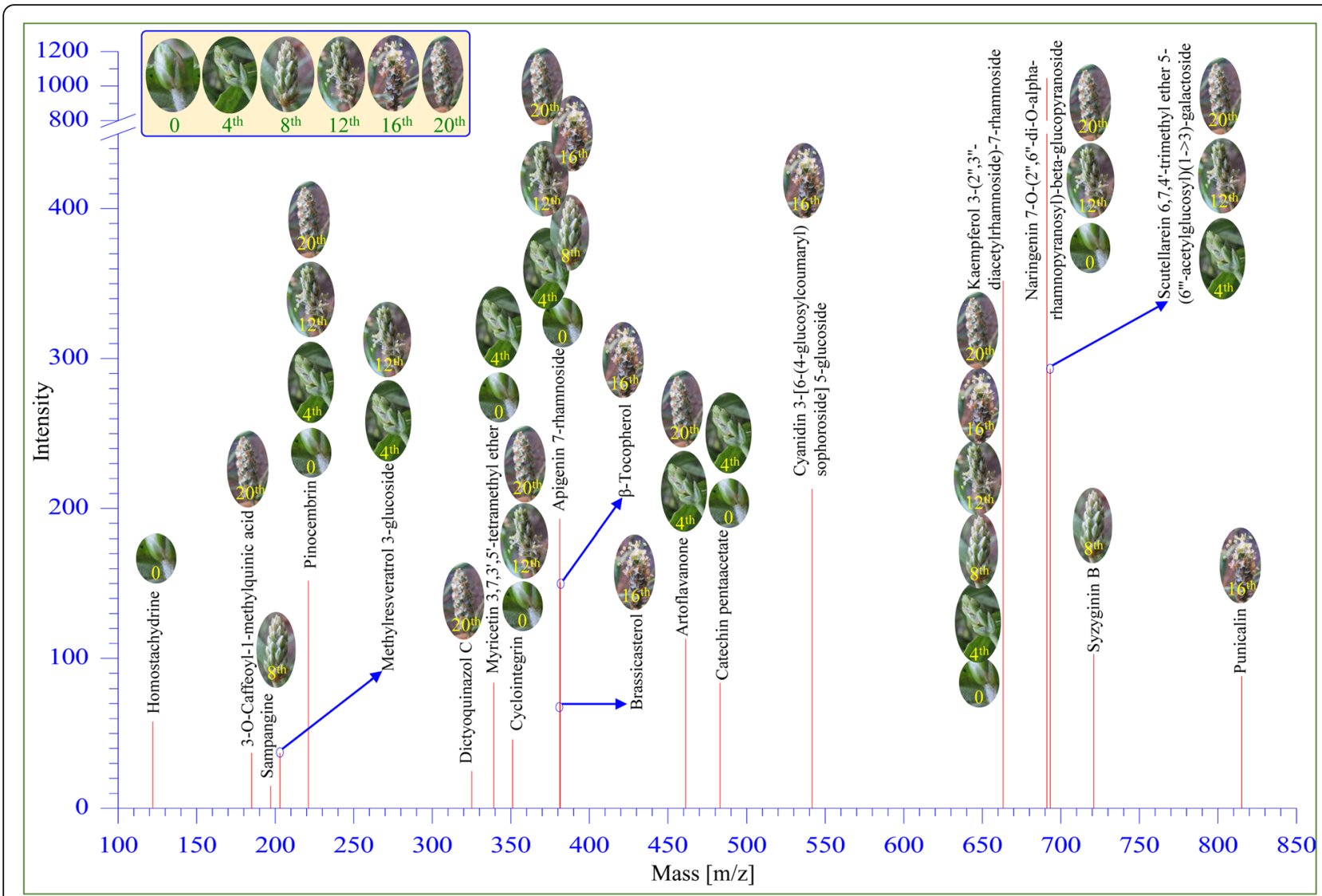

Fig. 7 Metabolites detected in developing fruit of psyllium. Each peak $(\mathrm{m} / \mathrm{z})$ represents identified metabolites. Images on peak show various developmental stages of psyllium fruit in which metabolites were identified

maturity (stage V, 20th day) only. Similarly, 3-OCaffeoyl-1-methylquinic acid have strong free radical scavenging activities and inhibition of lipid peroxidation [27] and it was first time characterized from the bamboo (Phyllostachys edulis). Interestingly, two metabolites, catechin pentaacetate and myricetin 3,7,3',5'-tetramethyl ether, were found particularly in the early stages (stage I, 0 day and II, 4th day). The flavonoids apigenin 7rhamnoside and kaempferol 3-(2",3"-diacetylrhamnoside)-7-rhamnoside were detected ubiquitously in all developmental stages. Most secondary metabolites, including kaempferol, catechin, and myricetin, are flavonoids and possess potent antioxidant activities [18, 45]. Other metabolites were differentially detected; however, pinocembrin is detected early and late stages of development. Several studies demonstrated the applications of pinocembrin both in vitro and in vivo and suggested that pinocembrin is a good pharmacological drug with potential antioxidative, anti-inflammatory, antitumor, and antimicrobial properties [48]. Previously, the spatial occurrence of metabolites was observed in the different plant parts of psyllium [45]. Similarly, spatial and developmental combinatorial metabolomics was reported in melon fruit, which revealed an extensive metabolic cross-talk [34]. They demonstrated that different developmental stages of a fruit contained a spatial composition of metabolites to which were attributed the organoleptic and nutritional qualities of the fruit [34].

\section{Conclusion}

Previously, a notable shifting of a complex network of metabolites and proteins was established for the developmental processes $[5,30]$. In the present study, a timedependent comparative study of metabolomics, including profiling of primary metabolites (FAs and amino acids), secondary metabolites, total flavonoids and total phenolic content, revealed that fruit development follows a diverse metabolic program. Different biochemical processes and activities (antioxidant and scavenging) undergo a progressive shift along with developmental stages and show a synchronised linkage with relevant metabolites. The availability of important long-chain PUFAs, such as LA, ALA, GLA and AA, have various biomedical and nutraceutical applications. To the best of our knowledge, this is the first study on the metabolic profiles and scavenging activities of developing psyllium 
fruiting body. Overall, it was concluded that developing psyllium fruiting bodies are a potential candidate to be explored further for nutraceutical applications. Further studies will focus on the validation of identified metabolites, and their integration with transcriptomics data, which will reveal the metabolic regulatory network of psyllium fruit development.

\section{Methods}

\section{Plant material and sample collection}

Seeds of Plantago ovata variety IS-3, procured from Seed Spices Research Station, Jagudan, Mehsana, Gujarat, India were sown in an open field (two plots containing garden soil, and each had a dimension of $63 \times 36 \mathrm{in}$.), and plants were grown under natural agro-climatic field conditions [45]. Each plot comprised of eight rows and each row contained about eight plants. Psyllium crops were maintained as per standard commercial practices [24]. Psyllium fruiting bodies were harvested at different developmental stages (0-20 days), and stored in liquid nitrogen for metabolomics and ROS scavenging studies, whereas for morphological studies, samples were stored in FAA (formaldehyde (40\%): acetic acid: aqueous ethanol (70\%); 5:5:90, v/v/v).

\section{Eidonomy and anatomy studies}

Floral development was studied morphologically with simple photography (DSLR, EOS760D, Canon, Japan) and cryo-scanning electron microscope (cryo-SEM, JSM$7600 \mathrm{~F}$, Jeol, Japan). The FAA preserved flower buds were dehydrated in ethanol (50 to $100 \%$ ), cut into $5 \mu \mathrm{m}$ thickness using microtome (MT-3, Nippon, Japan) and transverse sections were stained with $0.25 \%$ safranin. Sections were examined under light microscope (Axio imager M1, Carl Zeiss, Germany). For cry-SEM, FAA preserved samples were dehydrated in ethanol (50 to 100\%), frozen and cryosectioned by using attachments of cryo-SEM and analysed. All images were captured under different magnifications. The morphology of mature seed and dehiscence were studied under compound microscope (Olympus SZX2-ILLD, Tokyo, Japan), whereas the transverse section of mature fruiting body was observed with cryo-SEM.

\section{Primary metabolites profiling \\ Lipid extraction and fatty acid profiling}

Total lipids were extracted from preserved samples $(1 \mathrm{~g}$ biomass) using chloroform-methanol $(1: 2 \mathrm{v} / \mathrm{v})$ extraction method [41]. Total lipids were converted to corresponding fatty acid methyl esters (FAMEs) by transmethylation [33]. Samples were methylated with $\mathrm{NaOH}(1 \% \mathrm{v} / \mathrm{v}$ in methanol; $1 \mathrm{ml}$ ) in the vessels, followed by incubation at $55^{\circ} \mathrm{C}$ for $15 \mathrm{~min}$ in a water-bath. After that, methanolic $\mathrm{HCl}(5 \% \mathrm{v} / \mathrm{v} ; 2 \mathrm{ml})$ was added and further heated at $55^{\circ} \mathrm{C}$ for $15 \mathrm{~min}$. Deionized water-hexane mixture (1:2; $3 \mathrm{ml}$ ) was added to obtain phase separation. The derivative FAMEs were recovered and extracted in hexane (2 $\mathrm{ml}$ ), dried under $\mathrm{N}_{2}$ and dissolved in hexane $(200 \mu \mathrm{l})$. FAME samples were identified and quantified by gas chromatography coupled with mass spectrometer (GCMS-QP2010, Shimadzu, Japan) equipped with an auto-sampler (AOC-5000) and flame ionization detection (FID)/capillary column using previously optimised methods [33, 39].

Total saturated fatty acids (SFA) and unsaturated fatty acids (monounsaturated fatty acids, MUFA and polyunsaturated fatty acids, PUFA) were quantified by summation of percent quantity of corresponding fatty acids [41]. Unsaturation index (equation 1) [47], degree of unsaturation (equation 2) [63], atherogenic (equation 3) and thrombogenic (equation 4) indices [11] were calculated using the following equations-.

Unsaturation index $(U I)=\sum(U F A w \% \times$ number of double bonds $)$

Degree of unsaturation $(D U)=($ MUFA $w \%)+2 \times($ PUFA $w \%)$

$$
\text { Atherogenic index }(A I)=\frac{C 12+C 14+C 16}{\sum n 3 P U F A+\sum n 6 P U F A+\sum M U F A}
$$

Thrombogenic index $(T I)=\frac{C 14+C 16+C 18}{(0.5 \times n 6 \text { PUFA })+(3 \times n 3 P U F A)+(n 3 / n 6 P U F A)}$

\section{Amino acid profiling}

Amino acids were identified and quantified by HPLC system (Waters Alliance model, 2996-separation module with auto-sampler, USA) based on the phenylisothiocyanate (PITC) derivatisation method [26]. Total Protein was extracted from preserved fruiting bodies $(1 \mathrm{~g})$ using trichloroacetic acid (TCA) precipitation method. The total protein of each sample was hydrolysed by $\mathrm{HCl}(6 \mathrm{~N}$, $500 \mu \mathrm{l})$ in a sealed glass vessel by heating at $110^{\circ} \mathrm{C}$ for $24 \mathrm{~h}$ in an oven. After hydrolysis, vessels were broken and protein samples were vacuum dried in a desiccator. Protein samples and amino acid standard (AAS18, Sigma, St. Louis, Missouri, USA) were neutralised by adding the mixture of ethanol-water-TEA (triethylamine) $(2: 2: 1 \mathrm{v} / \mathrm{v} / \mathrm{v} ; 500 \mu \mathrm{l})$. Samples were derivatised by adding a mixture of ethanol-water-TEA-PITC (7:1:1:1 $\mathrm{v} / \mathrm{v} / \mathrm{v} / \mathrm{v} ; 500 \mu \mathrm{l})$. The reaction mixture was vortexed properly, kept at room temperature for $20 \mathrm{~min}$ and vacuum dried. Dried samples were dissolved in $\mathrm{Na}_{2} \mathrm{HPO}_{4}$ buffer $(400 \mu \mathrm{l} ; 5 \mathrm{mM}, \mathrm{pH} 7.4)$ containing acetonitrile (5\% v/v). 
Each sample was filtered with a $0.2 \mu \mathrm{m}$ membrane and amino acid composition was analysed using HPLC [32].

\section{Plant extract preparation}

Plant samples $(10 \mathrm{~g})$ were ground in liquid $\mathrm{N}_{2}$, transferred to aqueous methanol $(70 \%, \mathrm{v} / \mathrm{v})$ and kept overnight for extraction. The supernatant was collected by centrifugation at $8000 \mathrm{rpm}$ for $10 \mathrm{~min}$. The plant extracts were concentrated in a rotary evaporator $(150-100 \mathrm{mbar}$ at $37^{\circ} \mathrm{C}$ ), lyophilised and stored at $-20^{\circ} \mathrm{C}$ for further study.

To determine total phenolic content, flavonoid content, antioxidant activities, and scavenging activities, the absorbance reading of samples (plant extracts) were compared with a standard curve, which was drawn by the same method, using known amount of the corresponding standard. All tests were performed in triplicates, each containing three biological replicates and values were expressed as mean $\pm \mathrm{SE}$.

\section{Determination of total phenolic and total flavonoid contents}

Total phenolic content of the extract was determined by Folin-Ciocalteu (FC) reagents (Sigma-Aldrich, USA) using gallic acid as a standard [22, 33]. Folin-Ciocalteu reagent $(2.5 \mathrm{ml}$ of $0.2 \mathrm{~N})$ was mixed with extract, incubated for $5 \mathrm{~min}$, after that reaction gets neutralized by adding $2 \mathrm{ml}$ sodium carbonate $\left(\mathrm{Na}_{2} \mathrm{CO}_{3} ; 75 \mathrm{gl}^{-1}\right)$. The reaction mixtures were incubated further for $90 \mathrm{~min}$ at room temperature and absorbance was taken at $760 \mathrm{~nm}$. Total phenolic content was calculated as $\mathrm{mg} \mathrm{ml}^{-1}$ gallic acid per $100 \mathrm{mg}$ of extract from a standard curve.

To determine the total flavonoid content, $0.3 \mathrm{ml}$ $\mathrm{NaNO}_{2}(5 \%, \mathrm{v} / \mathrm{v})$ was added to the extract and mixture was incubated for $5 \mathrm{~min}$ at room temperature followed by addition of $0.3 \mathrm{ml} \mathrm{AlCl}_{3}(10 \%, \mathrm{v} / \mathrm{v})$ and $2 \mathrm{ml} \mathrm{NaOH}$ $(1 \mathrm{M})$. The reaction mixture was diluted with water and absorbance was recorded at $510 \mathrm{~nm}$. The total flavonoid content was calculated as $\mathrm{mg} \mathrm{ml}^{-1}$ quercetin per $100 \mathrm{mg}$ of extract from a standard curve $[57,66]$.

\section{Total antioxidant and scavenging activity}

Total antioxidant activity of plant extracts were measured by comparing $\mathrm{ABTS}^{+}$(2, 2'-azinobis-(3-ethylbenzothiazoline-6-sulfonic acid) radical cation scavenging capability $[22,49,58]$. The ABTS free radical cations were generated by mixing ABTS diammonium salt (7 $\mathrm{mM})$ solution with potassium persulfate $(2.45 \mathrm{mM})$ followed by incubation at room temperature for $12-16 \mathrm{~h}$ in the dark. The initial absorbance of $\mathrm{ABTS}^{+}$solution (at $735 \mathrm{~nm}$ ) was adjusted to $0.70 \pm 0.02$ by diluting with water. Diluted $\mathrm{ABTS}^{+}$solution $(1 \mathrm{ml})$ was mixed with a different concentration of the plant extracts or standard (1-5 $\mu \mathrm{g} \mathrm{ml}^{-1}$ trolox). The absorbance was recorded at
$735 \mathrm{~nm}$ after incubation; percentage inhibition was calculated and free radical cation scavenging activity was measured by comparing with trolox, which was used as a standard.

DPPH (2, 2-diphenyl-1-picrylhydrazyl) is a free radical, which turns from deep violet to pale yellow non-radical form of DPPH-H, due to the radical scavenging activity of antioxidants. The scavenging assay was performed by measuring change in the colour of DPPH solution [53]. The initial absorbance of DPPH stock solution $(0.024 \%$ $\mathrm{w} / \mathrm{v}$ in methanol) was adjusted about $0.98 \pm 0.02$ at 517 $\mathrm{nm}$ by diluting with methanol. DPPH working solution $(3 \mathrm{ml})$ was mixed with a different concentration of extracts and incubated at room temperature in the dark for overnight. The absorbance was recorded at $517 \mathrm{~nm}$ and DPPH radical scavenging activity was estimated using the equation 5 .

$$
\text { Scavenging activity }(\%)=\left[\frac{O D_{517} \text { of Control }- \text { OD } 517 \text { of Extract }}{O D_{517} \text { of Control }}\right] \times 100
$$

\section{Extraction and identification of secondary metabolites}

The each stage of fruiting body $(100 \mathrm{mg})$ was homogenised in liquid $\mathrm{N}_{2}$ and metabolites were extracted in icecold aqueous methanol $(70 \%, \mathrm{v} / \mathrm{v})$ followed by vortexing [45]. The samples were kept for sonication in an ultrasonic water bath (MRC, Holon, Israel) for one hour (at frequency $40 \mathrm{kHz} ; 25^{\circ} \mathrm{C}$ ). The samples were centrifuged $\left(20,000 \mathrm{rpm}\right.$ at $25^{\circ} \mathrm{C}$ for $\left.10 \mathrm{~min}\right)$, supernatant was collected and filtered through $0.2 \mu \mathrm{m}$ membrane. The filtered solution was used for metabolites analysis using LC coupled with TOF MS/MS system (Micromass, Waters, USA) in positive-ion mode [12]. The scanning range was $0-1000 \mathrm{~m} / \mathrm{z}$ with an acquisition rate of $0.25 \mathrm{~s}$ and inter-scan delay of $0.1 \mathrm{~s}$. The background of each spectrum was subtracted, the data smoothed, centered and peaks were integrated, using the Mass Lynx software version 4.1 (Micromass, Waters, USA). Metabolites were identified by comparing LC-TOF-MS/MS peaks using on-line database [67].

\section{Statistical analysis}

All experiments were carried out three times, each with three biological replicate sets and each set contained three replicates (i.e. total 27 samples were used for the study in $3 \times 3 \times 3$ pattern). Data for the each experiment was subjected to analysis of variance (ANOVA) to determine differences and expressed as the mean $\pm \mathrm{SE}$ (standard error of the mean). Statistical significance was determined at $p \leq 0.05$ using Tukey's multiple comparison method and mean values that were significantly different within a treatment are indicated by different 
letters. Total lipid composition was statistically analysed by principal component analysis (PCA) and a heat map was generated. Lipid data set was used to generate Pearson's correlation matrix, and PCA along with respective heat map was inferred [55, 61] using different software including Sigma Plot (ver. 12), SYSTAT (ver. 13) and Origin (ver. 15).

\section{Supplementary information}

Supplementary information accompanies this paper at https://doi.org/10 1186/s12870-020-2318-5.

Additional file 1: Table S1. Amino-acid composition of developing fruiting body of psyllium.

Additional file 2: Table S2. Basic chemical structure of metabolites identified in developing fruits of psyllium.

Additional file 3: Table S3. Probable metabolites identified by LC-MS (+ve mode) in developing fruit of psyllium.

Additional file 4: Figure S1. Loading plot of PC analysis (PCA) based on (A) fatty acid composition, (B) amino-acids and (C) total flavonoid and phenolic contents of developing psyllium fruit.

\section{Abbreviations}

ABTS: 2, 2'-azinobis-(3-ethylbenzothiazoline-6-sulfonic acid); Al: Atherogenicity index; ALA: Alpha-linolenic acid; ANOVA: Analysis of variance; DPPH: 2, 2diphenyl-1-picrylhydrazyl; DU: Degree of unsaturation; FA: Fatty acid; GCMS: Gas chromatography-mass spectrometry; GLA: Gamma-linolenic acid; HPLC: High-performance liquid chromatography; LA: Linoleic acid; LCMS: Liquid chromatography-mass spectrometry; MUFA: Mono unsaturated fatty acids; PCA: Principal component analysis; PUFA: Poly unsaturated fatty acids; ROS: Reactive oxygen species; SEM: Scanning electron microscope; SFA: Saturated fatty acids; TI: Thrombogenicity index; UI: Unsaturation index

\section{Acknowledgments}

CSIR-CSMCRI Communication No. PRIS- 72/2016. Analytical and Environmental Science Division and Centralized Instrument Facility, especially Dr. Harshad Brahmbhatt is duly acknowledged for helping in running samples for the analytical analysis.

\section{Authors' contributions}

Conceived and designed the experiments: AM and BJ. Performed the experiments: MKP and SJ. Analysed the data: MKP and AM. Wrote the paper: AM and MKP. All authors have read and approved the manuscript.

\section{Funding}

Council of Scientific and Industrial Research (CSIR), Govt. of India, New Delhi. Funding body was not involved in the design of the study and collection, analysis, and interpretation of data and in writing the manuscript.

\section{Availability of data and materials}

The datasets used and/or analysed during the current study available from the corresponding author on reasonable request

\section{Ethics approval and consent to participate}

Not applicable.

\section{Consent for publication}

Not applicable.

\section{Competing interests}

The authors declare that they have no competing interests.

\section{Author details}

'Division of Applied Phycology and Biotechnology, CSIR- Central Salt and Marine Chemicals Research Institute, G. B. Marg, Bhavnagar, Gujarat 364002. India. ${ }^{2}$ Present address: Department of Postharvest Science, Institute of
Postharvest and Food Sciences, Volcani Center, Agriculture Research Organization, HaMaccabim Road 68, 7505101 Rishon LeZion, Israel.

Received: 2 May 2019 Accepted: 27 February 2020

Published online: 14 March 2020

\section{References}

1. Al-Fayez M, Cai H, Tunstall R, Steward WP, Gescher AJ. Differential modulation of cyclooxygenase-mediated prostaglandin production by the putative cancer chemopreventive flavonoids tricin, apigenin and quercetin. Cancer Chemother Pharmacol. 2006;58:816-25.

2. Balasundram N, Sundram K, Samman S. Phenolic compounds in plants and Agri-industrial by-products: antioxidant activity, occurrence, and potential uses. Food Chem. 2006;99:191-203.

3. Baud S, Boutin JP, Miquel M, Lepiniec L, Rochat C. An integrated overview of seed development in Arabidopsis thaliana ecotype WS. Plant Physiol Biochem. 2002;40:151-60.

4. Beara IN, Lesjak MM, Jovin ED, Balog KJ, Anačkov GT, Orvcicì DZ, MimicaDukic NM. Plantain (Plantago L.) species as novel sources of flavonoid antioxidants. J Agric Food Chem. 2009:57:9268-73.

5. Bellaire A, Ischebeck T, Staedler Y, Weinhaeuser I, Mair A, Parameswaran S, Ito T, Schönenberger J, Weckwerth W. Metabolism and developmentintegration of micro computed tomography data and metabolite profiling reveals metabolic reprogramming from floral initiation to silique development. New Phytol. 2014;202:322-35.

6. Carrari F, Fernie AR. Metabolic regulation underlying tomato fruit development. J Exp Bot. 2006;57:1883-97.

7. Chaturvedi AK, Patel MK, Mishra A, Tiwari V, Jha B. The SbMT-2 gene from a halophyte confers abiotic stress tolerance and modulates ROS scavenging in transgenic tobacco. PLoS One. 2014;9:e111379.

8. Chevallier A. The Encyclopedia of Medicinal Plants. London: Dorling Kindersley; 1996. p. 336.

9. Choe $\mathrm{E}, \mathrm{Min}$ DB. Mechanisms of antioxidants in the oxidation of foods. Compr Rev Food Sci Food Saf. 2009;8(4):345-58.

10. Cook NC, Samman S. Flavonoids-chemistry, metabolism, cardioprotective effects, and dietary sources. J Nutr Biochem. 1996;7:66-76.

11. De Lorenzo A, Petroni ML, De Luca PP, Andreoli A, Morini P, lacopino L, Innocente I, Perriello G. Use of quality control indices in moderately hypocaloric mediterranean diet for treatment of obesity. Diabetes Nutr Metab. 2001;14:181-8.

12. De Vos RC, Moco S, Lommen A, Keurentjes JJ, Bino RJ, Hall RD. Untargeted large-scale plant metabolomics using liquid chromatography coupled to mass spectrometry. Nat Protoc. 2007;2:778-91

13. Embuscado ME. Spices and herbs: natural sources of antioxidants-a mini review. J Funct Foods. 2015;18:811-9.

14. Endo T, Taguchi H, Yosioka I. The glycosides of Plantago major. Chem Pharm Bull. 1981;20:1000-4.

15. Fait A, Hanhineva K, Beleggia R, Dai N, Rogachev I, Nikiforova VJ, Fernie AR Aharoni A. Reconfiguration of the achene and receptacle metabolic networks during strawberry fruit development. Plant Physiol. 2008;148:730-50.

16. FAO: Food and Agriculture Organization. Fats and fatty acids in human nutrition. In: Report of an FAO expert consultation. Rome: Food and Agriculture Organization of the United Nations; 2010

17. Giannasi DE. Flavonoids and evolution in the dicotyledons. In: Harborne JB, editor. The flavonoids: advances in research since 1980. Bostan: Springer; 1988. p. 479-504.

18. Gould KS, Lister C. Flavonoid functions plants. In Andersen M, Markham KR, editors. Flavonoids: chemistry, biochemistry and applications. Boca Raton: CRC Press; 2006. p. 397-441.

19. Groner B. Peptides as drugs: discovery and development. Weinheim: WileyVCH Verlag GmbH \& Co. KGaA; 2009.

20. Groot HD, Rauen U. Tissue injury by reactive oxygen species and the protective effects of flavonoids. Fundam Clin Pharmacol. 1998;12:249-55.

21. Harborne JB, Mabry TJ, Mabry H. The flavonoids. Bostan: Springer; 1975.

22. Hazra B, Biswas S, Mandal N. Antioxidant and free radical scavenging activity of Spondias pinnata. BMC Complement Altern Med. 2008:8:63.

23. Innis SM. Dietary (n-3) fatty acids and brain development. J Nutr. 2007;137: 855-9.

24. Jat RS, Reddy RN, Bansal R, Manivel P. Good agricultural practices for Isabgol. Anand: ICAR - Directorate of Medicinal and Aromatic Plants Research; 2015. 
25. Joshi M, Jha A, Mishra A, Jha B. Developing transgenic Jatropha using the SbNHX1 gene from an extreme halophyte for cultivation in saline wasteland. PLoS One. 2013;8:e71136.

26. Kwanyuen P, Burton JW. A modified amino acid analysis using PITC derivatization for soybeans with accurate determination of cysteine and half-cystine. J Am Oil Chem Soc. 2010;87:127-32.

27. Kweon MH, Hwang HJ, Sung HC. Identification and antioxidant activity of novel chlorogenic acid derivatives from bamboo (Phyllostachys edulis). J Agric Food Chem. 2001;49(10):4646-55.

28. Lebedev-Kosov VI. Flavonoids and iridoids of Plantago major and P. asiatica. Rast Resur. 1980;16:403-6.

29. Lien C, Lean T, Wen C, Mei-Yin C, Chun-Ching L. Immunomodulatory activities of flavonoids, monoterpenoids, triterpinoids, iridoid glycosides and phenolic compounds of Plantago species. Planta Med. 2003;69:600-4.

30. Lombardo VA, Osorio S, Borsani J, Lauxmann MA, Bustamante CA, Budde CO, Andreo CS, Lara MV, Fernie AR, Drincovich MF. Metabolic profiling during peach fruit development and ripening reveals the metabolic networks that underpin each developmental stage. Plant Physiol. 2011;157: 1696-710.

31. Marrelli M, Menichinib F, Stattia GA, Bonesia M, Duezc P, Menichinia F, Conforti F. Changes in the phenolic and lipophilic composition, in the enzyme inhibition and antiproliferative activity of Ficuscarica L. cultivar Dottato fruits during maturation. Food Chem Toxicol. 2012;50:726-33.

32. Mishra A, Jha B. Isolation and characterization of extracellular polymeric substances from micro-algae Dunaliella salina under salt stress. Bioresour Technol. 2009;100:3382-6.

33. Mishra A, Patel MK, Jha B. Non-targeted metabolomics and scavenging activity of reactive oxygen species reveal the potential of Salicornia brachiata as a functional food. J Funct Foods. 2015;13:21-31.

34. Moing A, Aharoni A, Biais B, Rogachev I, Meir S, Brodsky L, Allwood JW, Erban A, Dunn WB, Kay L, de Koning S. Extensive metabolic cross-talk in melon fruit revealed by spatial and developmental combinatorial metabolomics. New Phytol. 2011;190:683-96.

35. Moore DM, Williams CA, Yates B. Studies on bipolar disjunct species II. Plantago maritima. Bot Notiser. 1973;125:261-72.

36. Morales MT, Przybylski R. Olive oil oxidation. In: Aparicio R, Harwood JL, editors. Handbook of olive oil: analysis and properties, 2nd ed. New York: Springer; 2013. p. 479-522.

37. Nakamura Y, Teo NZ, Shui G, Chua CH, Cheong WF, Parameswaran S, Koizumi R, Ohta $\mathrm{H}$, Wenk MR, Ito T. Transcriptomic and lipidomic profiles of glycerolipids during Arabidopsis flower development. New Phytol. 2014;203:310-22.

38. Osorio S, Alba R, Nikoloski Z, Kochevenko A, Fernie AR, Giovannoni JJ. Integrative comparative analyses of transcript and metabolite profiles from pepper and tomato ripening and development stages uncovers speciesspecific patterns of network regulatory behavior. Plant Physiol. 2012;159(4): $1713-29$.

39. Pandey S, Patel MK, Mishra A, Jha B. Physio-biochemical composition and untargeted metabolomics of cumin (Cuminum cyminum L.) make it promising functional food and help in mitigating salinity stress. PLoS One. 2015;10:e0144469.

40. Pandey S, Patel MK, Mishra A, Jha B. In planta transformed cumin (Cuminum cyminum L.) plants, overexpressing the SbNHX1 gene showed enhanced salt endurance. PLoS One. 2016;11(7):e0159349.

41. Patel MK, Pandey S, Brahmbhatt HR, Mishra A, Jha B. Lipid content and fatty acid profile of selected halophytic plants reveal a promising source of renewable energy. Biomass Bioenergy. 2019b;124:25-32.

42. Patel MK, Tanna B, Gupta H, Mishra A, Jha B. Physicochemical, scavenging and anti-proliferative analyses of polysaccharides extracted from psyllium (Plantago ovata Forssk) husk and seeds. Int J Biol Macromol. 2019a;133:190-201.

43. Patel MK, Tanna B, Mishra A, Jha B. Physicochemical characterization, antioxidant and anti-proliferative activities of a polysaccharide extracted from psyllium (P. ovata) leaves. Int J Biol Macromol. 2018;118:976-87.

44. Patel MK, Joshi M, Mishra A, Jha B. Ectopic expression of SbNHX1 gene in transgenic castor (Ricinus communis L.) enhances salt stress by modulating physiological process. Plant cell Tiss Org. 2015;122:477-90.

45. Patel MK, Mishra A, Jha B. Non-targeted metabolite profiling and scavenging activity unveil the Nutraceutical potential of Psyllium (Plantago ovata Forsk). Front Plant Sci. 2016a;7:431.

46. Patel MK, Mishra A, Jha B. Untargeted metabolomics of halophytes. In: Kim S, editor. Marine Omics: principles and applications. Boca Raton: CRC Press; 2016b. p. 309-25.
47. Poerschmann J, Spijkerman E, Langer U. Fatty acid patterns in Chlamydomonas sp. as a marker for nutritional regimes and temperature under extremely acidic conditions. Microb Ecol. 2004;48:78-89.

48. Rasul A, Millimouno FM, Ali Eltayb W, Ali M, Li J, Li X. Pinocembrin: a novel natural compound with versatile pharmacological and biological activities. BioMed Res Int. 2013:379850.

49. Re R, Pellegrini N, Proteggente A, Pannala A, Yang M, Rice-Evans C. Antioxidant activity applying an improved ABTS radical cation decolorization assay. Free Radic Biol Med. 1999;26:1231-7.

50. Reardon W, Fitzpatrick DA, Fares MA, Nugent JM. Evolution of flower shape in Plantago lanceolata. Plant Mol Biol. 2009;71:241-50.

51. Rodríguez-Rodríguez MF, Sánchez-García A, Salas JJ, Garcés R, MartínezForce $E$. Characterization of the morphological changes and fatty acid profile of developing Camelina sativa seeds. Ind Crop Prod. 2013;50:673cc9.

52. Ross I. Plantago ovata. In: Medicinal plants of the world: chemical constituents, traditional and modern medicinal uses. vol 3. Totowa: Humana Press; 2005. p. 419-36.

53. Saeed N, Khan MR, Shabbir M. Antioxidant activity, total phenolic and total flavonoid contents of whole plant extracts Torilis leptophylla L. BMC Complement Altern Med. 2012;12:221.

54. Samuelsen AB. The traditional uses, chemical constituents and biological activities of Plantago major L. A review. J Ethnopharmacol. 2000;71:1-21.

55. Singh VK, Mishra A, Haque I, Jha B. A novel transcription factor-like gene SbSDR1 acts as a molecular switch and confers salt and osmotic endurance to transgenic tobacco. Sci Rep. 2016;6:31686.

56. Talukder P, Talapatra S, Ghoshal N, Raychaudhuri SS. Antioxidant activity and HPLC analysis of phenolic compounds during in vitro callus culture of Plantago ovata Forsk and effect of exogenous additives on accumulation of phenolic compounds. J Sci Food Agric. 2015;96:232-44.

57. Tanna B, Brahmbhatt HR, Mishra A. Phenolic, flavonoid, and amino acid compositions reveal that selected tropical seaweeds have the potential to be functional food ingredients. J Food Process Preserv. 2019;43(12):e14266.

58. Tanna B, Choudhary B, Mishra A. Metabolite profiling, antioxidant, scavenging and anti-proliferative activities of selected tropical green seaweeds reveal the nutraceutical potential of Caulerpa spp. Algal Res. 2018;36:96-105.

59. Thai QD, Tchoumtchoua J, Makropoulou M, Boulaka A, Meligova AK, Mitsiou DJ, Mitakou S, Michel S, Halabalaki M, Alexis MN, Skaltsounis LA. Phytochemical study and biological evaluation of chemical constituents of Platanus orientalis and Platanus $\times$ acerifolia buds. Phytochemistry. 2016;130:170-81.

60. Tiwari V, Chaturvedi AK, Mishra A, Jha B. Introgression of the SbASR-1 gene cloned from a halophyte Salicornia brachiata enhances salinity and drought endurance in transgenic groundnut (Arachis hypogaea) and acts as a transcription factor. PLoS One. 2015;10:e0131567.

61. Udawat P, Jha RK, Sinha D, Mishra A, Jha B. Overexpression of a cytosolic abiotic stress responsive universal stress protein (SbUSP) mitigates salt and osmotic stress in transgenic tobacco plants. Front Plant Sci. 2016;7:518.

62. Yang L, Chen Q, Wang F, Zhang G. Antiosteoporotic compounds from seeds of Cuscuta chinensis. J Ethnopharmacol. 2011;135:553-60.

63. Yu X, Zhao P, He C, Li J, Tang X, Zhou J, Huang Z. Isolation of a novel strain of Monoraphidium sp. and characterization of its potential application as biodiesel feedstock. Bioresour Technol. 2012;121:256-62.

64. Zhang J, Wang X, Yu O, Tang J, Gu X, Wan X, Fang C. Metabolic profiling of strawberry (Fragariax ananassa Duch.) during fruit development and maturation. J Exp Bot. 2010;62(3):1103-18.

65. Zhang W, Li C, You L, Fu X, Chen YS, Luo YQ. Structural identification of compounds from Toona sinensis leaves with antioxidant and anticancer activities. J Funct Foods. 2014;10:427-35.

66. Zhishen J, Mengcheng T, Jianming W. The determination of flavonoid contents in mulberry and their scavenging effects on superoxide radicals. Food Chem. 1999;64:555-9.

67. Zhu ZJ, Schultz AW, Wang J, Johnson CH, Yannone SM, Patti GJ, Siuzdak G. Liquid chromatography quadrupole time-of-flight mass spectrometry characterization of metabolites guided by the METLIN database. Nat Protoc. 2013;8:451-60.

\section{Publisher's Note}

Springer Nature remains neutral with regard to jurisdictional claims in published maps and institutional affiliations. 